\title{
A High CD4+ T cell HIV Patient with Progressive Multifocal Leukoencephalopathy: A Rare Case Report
}

Dr. Amber Mittal*, Dr. Ganesh Koppad

Postgraduate Resident, Department of Medicine, NSCB Medical College, Jabalpur, Madhya Pradesh, India

DOI: $10.36347 /$ sjams.2020.v08i08.016

| Received: 13.08.2020 | Accepted: 20.08.2020 | Published: 22.08.2020

*Corresponding author: Dr. Amber Mittal

Abstract

Progressive multifocal leukoencephalopathy (PMLE) is an AIDS defining disease often arising in HIV (human immunodeficiency virus) disease patients with low CD4 T cell count, and rarely among those with more than 500 CD4 $\mathrm{T}$ cell $/ \mathrm{mm}^{3}$. Definite diagnosis requires JC Virus (JCV) isolation in cerebrospinal fluid (CSF) or in brain tissue. A 31 year-old man was diagnosed with HIV1, never having any AIDS-defining illness since august'18. Combined antiretroviral therapy was started. In February 2019 right hemiparesis along with cognitive and behaviour disturbances. His CD4 $\mathrm{T}$ cell count was of $475 / \mathrm{mm}^{3}$. Brain MRI was done showing asymmetrical demyelinating lesions. Normal cerebrospinal fluid (CSF) findings other than mononuclear pleocytosis. PMLE was diagnosed on the basis of clinical and radiological findings. Treatment should not be delayed when a probable diagnosis exists even if CD4 T cell count is above $500 / \mathrm{mm}^{3}$. Repeated lumbar puncture with JCV determinations should be done in the advent of new/worsen neurological symptoms and evidence of demyelination showed in MRI.

Keywords: Progressive multifocal leukoencephalopathy; JC Virus; AIDS; CD4 T cell count.

Copyright @ 2020: This is an open-access article distributed under the terms of the Creative Commons Attribution license which permits unrestricted use, distribution, and reproduction in any medium for non-commercial use (NonCommercial, or CC-BY-NC) provided the original author and source are credited.

\section{INTRODUCTION}

Progressive multifocal leukoencephalopathy (PMLE) is a demyelinating disease of the central nervous system. A polyomavirus was identified as the etiological agent in 1967, named in 1971 as JC Virus (JCV), after the initials of the patient where the virus was first isolated (John Cunningham) [1, 2]. It occurs in immunocompromised patients; nowadays mainly in HIV infected ones. The probability of a HIV patient developing neurological symptoms and PMLE lesions is higher amongst the ones with a lower immunological status, expressed by a CD4 $\mathrm{T}$ cell count lower than $200 / \mathrm{mm}^{3}[3,4]$.

The diagnosis may be presumptive with the combination of neurological symptoms (visual disturbance, cognitive and behavioural alterations, seizures, and motor disorders with paralysis or akinesia) and characteristic magnetic resonance imaging (MRI) findings. Positive JCV in cerebrospinal fluid (CSF) or brain tissue specific anomalies, in association with clinical features and MRI findings, confirm PMLE [5]. Patients with suspicion of having PMLE should undergo a lumbar puncture with JCV search by means of PCR
We describe a clinical case of an HIV infected man under Anti-retroviral therapy (ART) with a high CD4 $\mathrm{T}$ cell count that developed neurological symptoms and characteristic PMLE brain lesions.

\section{Case Report}

31 year male HIV patient (since Aug'18) presented in Feb'19 with right hemiparesis along with cognitive and behaviour dysfunctions since 3 days and one episode of abnormal body movements. Patient was taking ATT for tubercular pleural effusion since 5 months and was on ART since 4 months.

O/E Vitals were stable and GCS was 10/15. Pupils were $2-3 \mathrm{~mm}$, equal in size, sluggishly reacting to light. Right side was hypotonic with diminished reflexes. Neck rigidity and kernig's sign were present. Rest systemic examination was normal.

Blood profile was unremarkable and he had no evidence of infectious disease elsewhere and no signs of systemic infection were found. Thyroid, renal and hepatic profile was normal and there were no vitamin deficiencies. A lympho- or myeloproliferative disorder and an inflammatory or granulomatosis disease were also ruled out. 
CD4 count was $475 / \mathrm{mm} 3$.CSF examination revealed normal glucose $(0.56 \mathrm{~g} / \mathrm{dl})$ and protein $(0.33$ $\mathrm{g} / \mathrm{L}$ ) levels with 60 leucocytes (42 mononuclear cells).

MRI of brain showed asymmetric T2- FLAIR hyperintense lesions in bilateral parieto-occipital white matter and these lesions were predominantly hypointense on T1W images. The lesions also involved peri rolandic region, left cerebral peduncle and right cerebellar hemisphere. There was no midline shift.
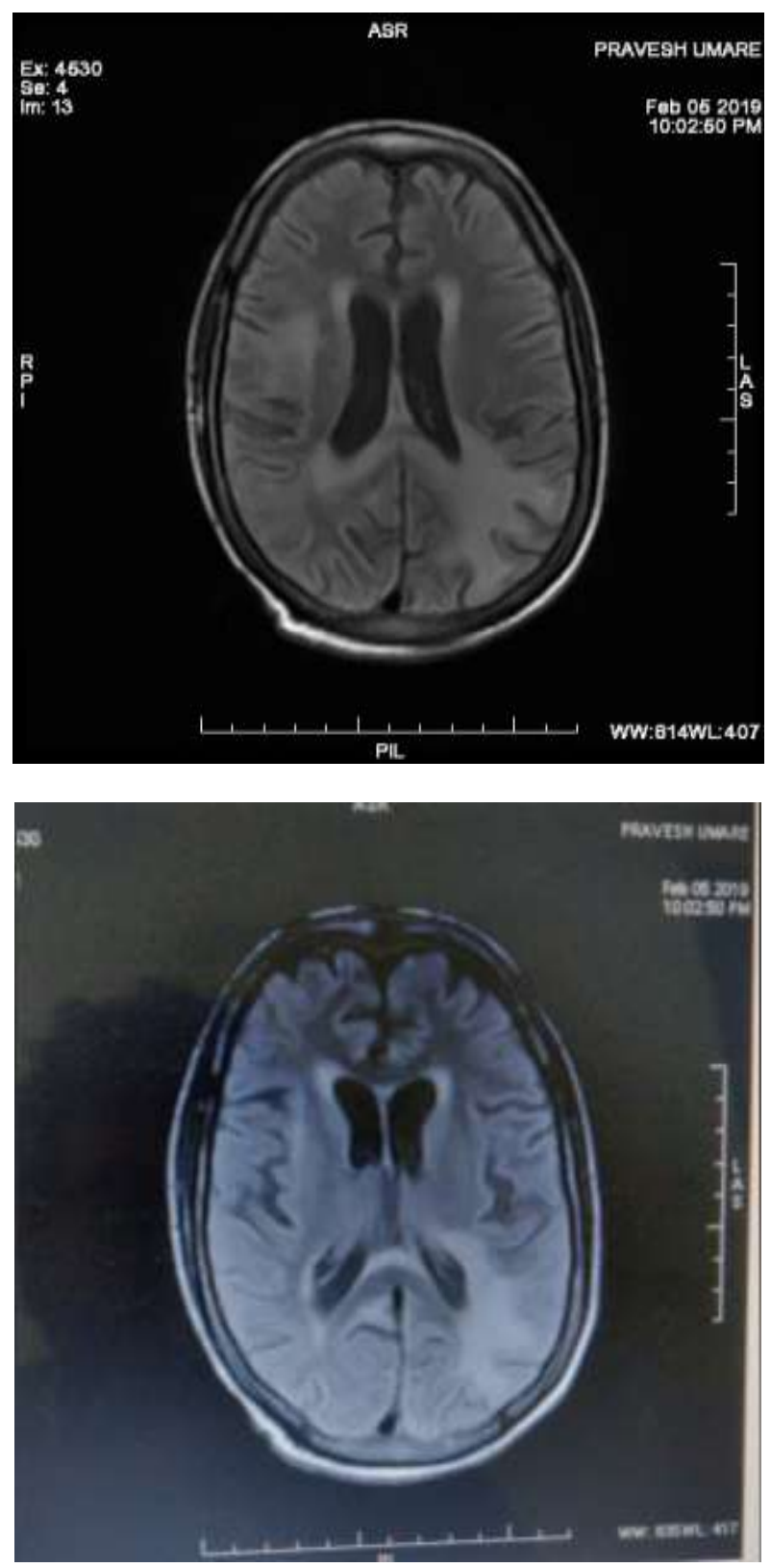

The patient was diagnosed as progressive multifocal leukoencephalopathy on the basis of clinical and radiological findings.

\section{DISCUSSION}

PMLE is an AIDS defining disease often seen in HIV patients with low CD4+ count and rarely among those with higher CD4 count. Patients often presents with visual deficits, mental impairment, weakness including hemi or monoparesis. Seizures occur in $20 \%$ of patients.

This case report shows how a definite PMLE diagnosis is rare and difficult to achieve in a patient with a high CD4 $\mathrm{T}$ cell count and under ARV. It is known that in HIV patients, PMLE often arises in severe immunocompromised states, when CD4 T cell count is lower than $200 / \mathrm{mm}^{3}$. Nevertheless, cases have been described with CD4 $\mathrm{T}$ cell count higher than that value but rare. It is well known that JCV cannot infect T lymphocytes or bind to $\mathrm{T}$ cell membranes. It seems that JCV uses B lymphocytes as a 'Trojan horse' to reach the brain exceeding the blood-brain barrier, and it happens when the reactivation process starts, when an immunosuppression state is achieved, because it can induce the loss of specific immune cells that may allow the beginning of active replication and infection as well as changes in JCV regulatory region [6].

Nowadays, it is not known which 'level' of immunodepression is needed in an HIV patient for JCV to turn from a latent to a replicative state, or if there are some other means for JCV to reach the brain and infect oligodendrocytes rather than the 'B lymphocyte way'.

Sometimes in the course of the disease, PMLE diagnosis was questioned, mainly due to the relatively high CD4 T cell count and in spite of the initial findings in MRI. MRI is the best imaging tool to diagnose PMLE, with typical appearance in $90 \%$ of the patients, usually with patchy and commonly non-enhancing white matter lesions, usually bilateral and asymmetric, and with no mass effect. Yet, some demyelinating diseases may present almost with the same characteristics, but some of them with mass effect [7]. HIV-leukoencephalitis is the main differential diagnosis, but it seems that lesions are less diffuse, more symmetric, not visible on T1 $\mathrm{w}$ and less intense on T2w sequence $[8,9]$.

\section{Conclusion}

Clinical symptoms and signs together with typical MRI findings among patients with high CD4 T cell count and under ARV should be considered and treated as PMLE. The progression of the disease may correlate with a higher replication of the JCV. Several lumbar punctures with JCV PCR in CSF should be done, but a negative result should not delay the start of antiretroviral treatment in those patients with CD4 T cell count even above $500 / \mathrm{mm}^{3}$. 


\section{REFRENCES}

1. Focosi D, Marco T, Kast RE, Maggi F, CeccheriniNelli L, Petrini M. Progressive multifocal leukoencephalopathy: what's new? Neuroscientist. 2010;16(3):308-323.

2. Zheng HC, Yan L, Cui L, Guan YF, Takano Y. Mapping the history and current situation of research on John Cunningham virus - a bibliometric analysis. BMC Infect Dis. 2009; 9:28.

3. Khanna N, Elzi L, Mueller NJ, Garzoni C, Cavassini M, Fux CA, Vernazza P, Bernasconi E, Battegay M, Hirsch HH, Swiss HIV Cohort Study. Incidence and outcome of progressive multifocal leukoencephalopathy over 20 years of the Swiss HIV Cohort Study. Clinical infectious diseases. 2009 May 15;48(10):1459-66.

4. Engsig FN, Hansen AB, Omland LH, Kronborg G, Gerstoft J, Laursen AL, Pedersen C, Mogensen CB, Nielsen L, Obel N. Incidence, clinical presentation, and outcome of progressive multifocal leukoencephalopathy in HIV-infected patients during the highly active antiretroviral therapy era: a nationwide cohort study. The Journal of infectious diseases. 2009 Jan 1;199(1):77-83.

5. Cinque P, Koralnik IJ, Gerevini S, Miro JM, Price RW. Progressive multifocal leukoencephalopathy in HIV-1 infection. Lancet Infect Dis. 2009;9(10):625-636.

6. Sabath BF, Major EO. Traffic of JC virus from sites of initial infection to the brain: the path to progressive multifocal leukoencephalopathy. J Infect Dis. 2002;186 Suppl 2:S180-186.

7. Kingsley PB, Shah TC, Woldenberg R. Identification of diffuse and focal brain lesions by clinical magnetic resonance spectroscopy. NMR Biomed. 2006;19(4):435-462.

8. Sarrazin JL, Soulie D, Derosier C, Lescop J, Schill $\mathrm{H}$, Cordoliani YS. [MRI aspects of progressive multifocal leukoencephalopathy]. J Neuroradiol. 1995;22(3):172-179.

9. Shah R, Bag AK, Chapman PR, Cure JK. Imaging manifestations of progressive multifocal leukoencephalopathy. Clin Radiol. 2010;65(6):431439. 